\title{
Case Report: Spontaneous simultaneous coronary and carotid dissection in a young cannabis user [version 1; peer review: 1
}

\section{approved]}

\author{
Hassen Ibn Hadj Amor(D1, Imen Touil(i)2, Seif Boukriba (iD), Skander Bouchnak (D)1, \\ Salma Kraiem (iD), Ramzi Rouabhia (iD)
}

${ }^{1}$ Cardiology Department, Taher Sfar university hospital, Mahdia, 5100, Tunisia

2Pneumology Department, Taher Sfar university hospital, Mahdia, 5100, Tunisia

${ }^{3}$ Radiology Department, Rabta University Hospital, Tunis, 1007, Tunisia

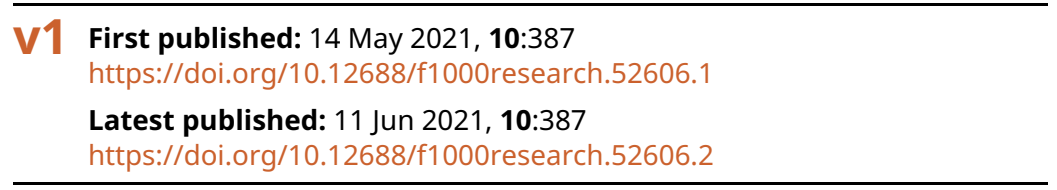

\section{Abstract}

Due to legalization of its consumption in some countries and its medical use as well as low toxic potential, cannabis remains the most widely used drug around the world and the rate of usage is only increasing.

Nevertheless, there are several case reports of vascular complications following cannabis use even in young people without cardiovascular risk factors. We report the case of a cannabis smoker presenting to the emergency room for an ischemic stroke associated with an acute coronary syndrome related to a spontaneous simultaneous double dissection of the carotid artery and the left anterior descending artery, with a favourable outcome under medical treatment. This case shows the seriousness of complications due to the cannabis consumption, hence the need to limit or even prohibit its consumption.

Keywords

Cannabis, coronary dissection, carotid dissection, acute coronary syndrome, ischemic stroke.

\section{Open Peer Review \\ Approval Status \\ 1 2 \\ version 2 \\ (revision) \\ 11 Jun 2021 \\ version 1 \\ 14 May 2021

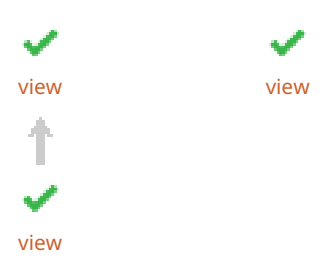 \\ 1. Rania Hammami iD, University of Medicine of Sfax, Sfax, Tunisia \\ 2. Amr Ashry AD, Alder Hey Children Hospital, Liverpool, UK \\ Assiut University, Assiut, Egypt}

Any reports and responses or comments on the article can be found at the end of the article. 
Corresponding authors: Hassen Ibn Hadj Amor (hassenibnhadjamor@yahoo.fr), Imen Touil (imenn.touil@gmail.com)

Author roles: Ibn Hadj Amor H: Conceptualization, Data Curation, Formal Analysis, Funding Acquisition, Methodology, Resources, Visualization, Writing - Original Draft Preparation, Writing - Review \& Editing; Touil I: Conceptualization, Data Curation, Investigation, Methodology, Visualization; Boukriba S: Resources, Software, Visualization; Bouchnak S: Conceptualization, Formal Analysis, Funding Acquisition, Investigation, Software; Kraiem S: Data Curation, Formal Analysis, Resources, Software, Writing - Original Draft Preparation; Rouabhia R: Formal Analysis, Resources, Software

Competing interests: No competing interests were disclosed.

Grant information: The author(s) declared that no grants were involved in supporting this work.

Copyright: (c) $2021 \mathrm{Ibn}$ Hadj Amor $\mathrm{H}$ et al. This is an open access article distributed under the terms of the Creative Commons Attribution License, which permits unrestricted use, distribution, and reproduction in any medium, provided the original work is properly cited.

How to cite this article: Ibn Hadj Amor H, Touil I, Boukriba S et al. Case Report: Spontaneous simultaneous coronary and carotid dissection in a young cannabis user [version 1; peer review: 1 approved] F1000Research 2021, 10:387

https://doi.org/10.12688/f1000research.52606.1

First published: 14 May 2021, 10:387 https://doi.org/10.12688/f1000research.52606.1 


\section{Introduction}

Cannabis, known as marijuana, is the most widely used illicit drug in the world. Its consumption is steadily increasing due to its legalization in several countries and its recreational and medical use ${ }^{1}$.

Although the mechanisms are not yet well established, the devastating effect of cannabis abuse on the cardiovascular system, even in the absence of other cardiovascular risk factors, is demonstrated.

Diverse cases of cannabis-related acute coronary syndrome (ACS), ischemic strokes or vascular attacks associated with cannabis use have been reported ${ }^{2}$.

Herein, we present the first case of cannabis-induced spontaneous simultaneous double coronary and carotid dissection.

\section{Case report}

A 32-year-old Caucasian student male was admitted to our intensive care unit (ICU) for right total hemiplegia and aphasia evolving for 4 hours associated with chest discomfort.

His past medical history revealed no cardiovascular risk factors or symptoms. He was occasional cannabis smoker and reported daily consumption in the last 5 days.

An initial exam showed stable hemodynamic parameters, the patient was conscious and executed orders successfully with his left extremities, but he had an incomprehensive verbal response. An electrocardiogram showed ST-segment elevation in the anterior leads, compatible with an ST-elevation myocardial infarction (STEMI).

Emergent contrast-enhanced computed tomography (CT) scan showed spontaneous hyper-density regarding the left frontal cortex, a sub-cortical left frontal, and multiple supratentorial regions of hypodensity in a vascular distribution occurred in the white matter- grey-matter. (Figure 1) In the cervicothoracic section, it showed thrombosed dissection of the left internal carotid artery, extending over $21 \mathrm{~mm}$ in height. (Figure 2)

The evolution was marked by spontaneous regression within 30 minutes of ST segment elevation and appearance of anterior negative $\mathrm{T}$ waves.

Echocardiography showed limited left ventricular anterior and apical wall motion abnormalities with conserved systolic ejection fraction (LVEF: 55\%). The laboratory results were normal except for elevated cardiac enzymes.

Early cardiac catheterization showed an acute thrombotic dissection of the proximal left descending artery with TIMI III blood flow. (Figure 3) The circumflex artery and the right coronary artery were normal. We decided to respect the lesion, and to put him under double antiplatelet therapy (clopidogrel $75 \mathrm{mg}$ per day, aspirin $160 \mathrm{mg}$ per day), unfractionated heparin, nitrates, and bisoprolol.

A second cerebral CT scan followed 48 hours later and showed favourable evolution of the cerebral lesions, so we decided to continue conservative treatment with close follow up. In-hospital outcome was favourable, with regression of aphasia and hemiplegia starting from the fifth day of the hospitalization. He was discharged after 15 days on clopidogrel $75 \mathrm{mg}$ per day, aspirin $160 \mathrm{mg}$ per day, atorvastatin $40 \mathrm{mg}$ per day, and bisoprolol $2.5 \mathrm{mg}$ per day.

At 3-month clinical control check-up, he retained right lower limb motor sequelae. Cardiac control showed the absence of symptoms, with a good electrocardiographic and echocardiographic evolution (LVEF: 60-65\%).

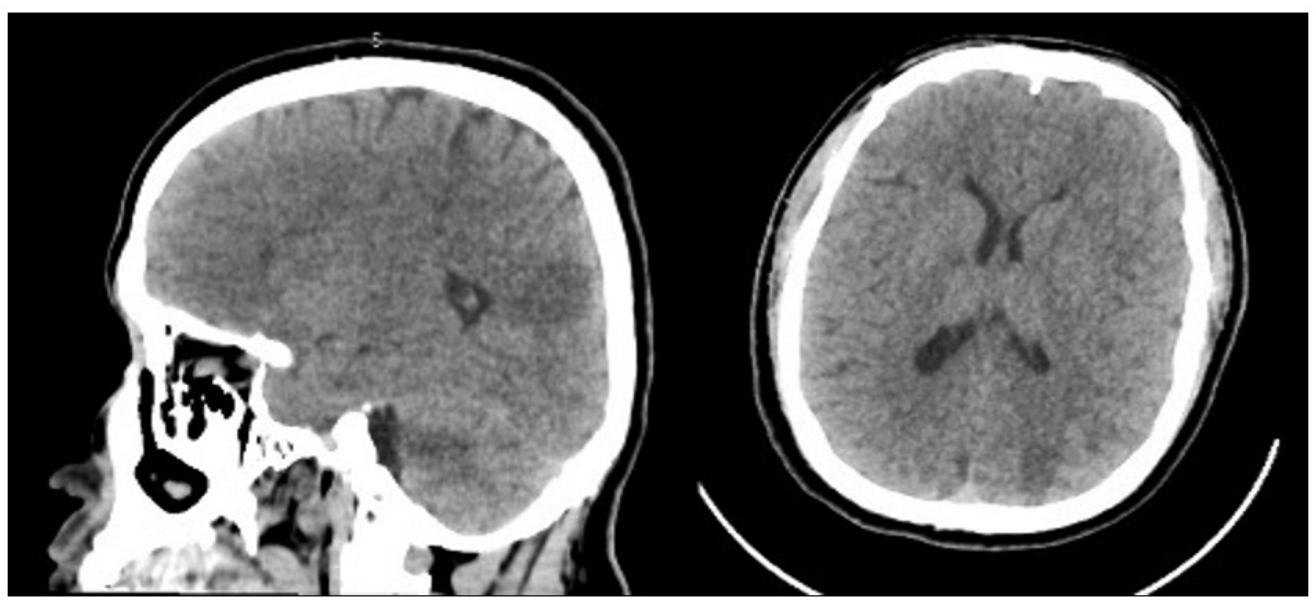

Figure 1. contrast-enhanced computed tomography (CT) scan showed embolic cerebral infraction consisting in multiple supratentorial regions of hypodensity in a vascular distribution occurring in the white matter-gray-matter. 


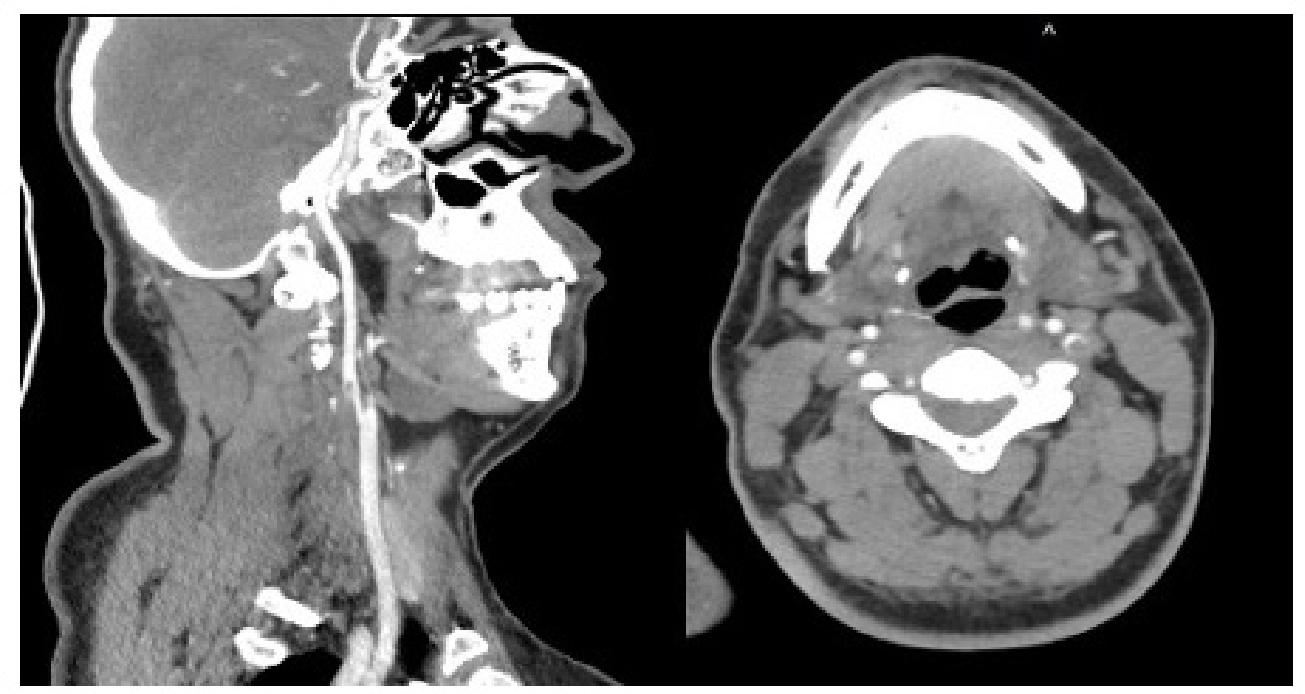

Figure 2. contrast-enhanced computed tomography (CT) scan showed in the cervicothoracic section a thrombosed dissection of left internal carotid.

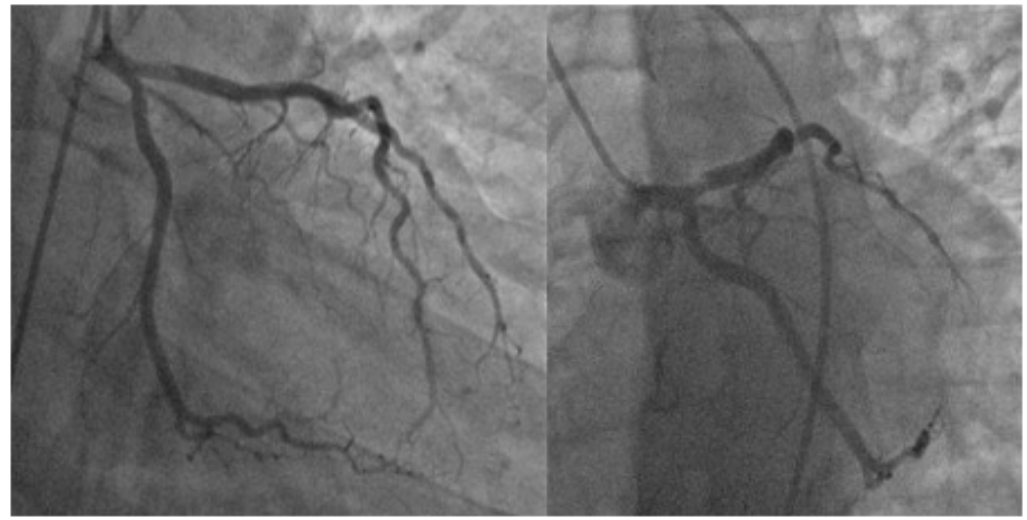

Figure 3. Coronary angiography showed an acute thrombotic type 1 dissection of the proximal left descending artery with TIMI III blood flow.

\section{Discussion}

Marijuana consumption has been considered benign for a long time, but multiple cardiovascular effects have been described ${ }^{3}$.

At low or moderate doses, smoked marijuana increases sympathetic activity and reduces parasympathetic activity resulting in tachycardia, hypertension and may induce atrial fibrillation ${ }^{4}$. conversely, high doses cause bradycardia and hypotension ${ }^{5}$.

In experimental conditions, cannabis causes arteriolar vasodilation which probably explains its low toxic potential, however, this is not always the rule. Contrasting effects of cannabinoids have been shown, responsible for vasoconstriction with acute coronary syndrome, stroke, or peripherical arteriopathy as complications ${ }^{6}$.

Marijuana abuse can cause myocardial ischemia by various mechanisms including rupture of high-risk pre-existing plaques ${ }^{7}$, coronary vasospasm, and coronary embolism ${ }^{8}$.

Hemodynamic and oxidative stress weakens arterial walls and promotes plaque rupture thus allowing platelet activation, thrombus formation, and infarction ${ }^{9,10}$

Arterial fragility in our case as a consequence of oxidative stress, is the most logical mechanism explaining spontaneous double dissection. 
A recent systematic review of all cases of cannabis-induced myocardial infarction, showed male predominance $(95,2 \%)$. Angiographic findings reveal involved occluded coronary arteries in $63,2 \%$ whose involvement concerned the left anterior descending artery in $42.1 \%$ of cases. Conservative management with medical observation was sufficient in $46.7 \%$ of patients ${ }^{2}$.

Cerebrovascular ischemic lesions are common in marijuana abuse where reversible cerebrovascular spasm is most often the cause $^{11}$.

Spontaneous artery dissection is a rare cause of ACS or stoke. It is generally associated with particular clinical situations: the use of contraceptives, pregnancy, Marfan syndrome, connective tissue disorders, trauma, and cocaine abuse ${ }^{12}$.

Several cases of cannabis-induced dissection have been reported in the literature, affecting coronary and cerebral arteries but also the aorta and renal arteries ${ }^{13,14}$.

No previous case of spontaneous simultaneous coronary and carotid dissection related to cannabis use has been reported.
There is no proven therapeutic strategy for cannabis-related dissection as the literature is limited to case studies. Double antiplatelet therapy without vascular intervention can be attempted in hemodynamically stable patients ${ }^{2}$.

\section{Conclusion}

This case highlights cannabis-related coronary and cerebral complications in in early adulthood.

An increase in such cases is to be expected in the face of legalization of cannabis consumption and medical use which is spreading in several countries. If the increase in global consumption becomes unavoidable, the search for predictive factors of complications due to cannabis consumption appears necessary to avoid these serious consequences.

\section{Patient consent}

Written informed consent for publication of their clinical details and/or images was obtained from the patient.

\section{Data availability statement}

All data underlying the results are available as part of the article and no additional source data are required.

\section{References}

1. Goyal $\mathrm{H}$, Awad $\mathrm{HH}$, Ghali JK: Role of cannabis in cardiovascular disorders. J Thorac Dis. 2017; 9(7): 2079-2092.

PubMed Abstract | Publisher Full Text | Free Full Text

2. Patel RS, Kamil SH, Bachu R, et al.: Marijuana use and acute myocardial infarction: a systematic review of published cases in the literature. Trends Cardiovasc Med. 2020; 30(5): 298-307. PubMed Abstract | Publisher Full Text

3. Filali T, Lahidheb D, Gommidh M, et al.: Spontaneous multivessel coronary artery dissection associated with cannabis use. J Cardiol Cases. 2012; 7(1): e4-7.

PubMed Abstract | Publisher Full Text | Free Full Text

4. Singh A, Saluja S, Kumar A, et al:: Cardiovascular complications of marijuana and related substances: a review. Cardiol Ther. 2018; 7(1): 45-59. PubMed Abstract | Publisher Full Text | Free Full Text

5. Fisher BAC, Ghuran A, Vadamalai V, et al.: Cardiovascular complications induced by cannabis smoking: a case report and review of the literature. Emerg Med J. 2005; 22(9): 679-80.

PubMed Abstract | Publisher Full Text | Free Full Text

6. Dines AM, Wood DM, Galicia M, et al:: Presentations to the emergency department following cannabis use--a multi-centre case series from ten European countries. J Med Toxicol. 2015; 11(4): 415-21. PubMed Abstract | Publisher Full Text | Free Full Text

7. Mittleman MA, Lewis RA, Maclure $\mathrm{M}$, et al.: Triggering myocardial infarction by marijuana. Circulation. 2001; 103(23): 2805-9. PubMed Abstract | Publisher Full Text
8. Velibey $Y$, Sahin $S$, Tanık O, et al:: Acute myocardial infarction due to marijuana smoking in a young man: guilty should not be underestimated. Am J Emerg Med. 2015; 33(8): 1114.e1-3. PubMed Abstract | Publisher Full Text

9. UI Haq E, Shafiq A, Khan AA, et al.: "Spice" (Synthetic marijuana) induced acute myocardial infarction: a case series. Case Rep Cardiol. 2017; 2017: 9252463.

PubMed Abstract | Publisher Full Text | Free Full Text

10. Shah PK: Mechanisms of plaque vulnerability and rupture. J Am Coll Cardiol. 2003; 41 (4 Suppl S): 15S-22S. PubMed Abstract | Publisher Full Text

11. Mouzak A, Agathos $P$, Kerezoudi $E$, et al.: Transient ischemic attack in heavy cannabis smokers--how 'safe' is it? Eur Neurol. 2000; 44(1): 42-4. PubMed Abstract | Publisher Full Text

12. Schmid J, Auer J: Spontaneous coronary artery dissection in a young man - case report. J Cardiothorac Surg. 2011; 6(1): 22. PubMed Abstract | Publisher Full Text | Free Full Text

13. Lou JY, Randhawa MS, Hornacek D, et al.: Images in vascular medicine. Spontaneous renal artery dissection in a cannabis user. Vasc Med. 2015; 20(4): 379-380. PubMed Abstract | Publisher Full Text

14. Mason EK, Gak AE, Finno JG, et al.: Thoracic aortic dissection associated with marijuana use. J Emerg Med. 2019; 57(2): 235-7. PubMed Abstract | Publisher Full Text 


\section{Open Peer Review}

\section{Current Peer Review Status:}

\section{Version 1}

Reviewer Report 01 June 2021

https://doi.org/10.5256/f1000research.55907.r85461

(C) 2021 Hammami R. This is an open access peer review report distributed under the terms of the Creative Commons Attribution License, which permits unrestricted use, distribution, and reproduction in any medium, provided the original work is properly cited.

\section{Rania Hammami}

Cardiology Department, Hedi Chaker University Hospital, University of Medicine of Sfax, Sfax, Tunisia

I would like first to thank the authors for this interesting case of coronary and carotid Spontaneous dissection in a young patient after cannabis consumption! After reviewing the literature, this clinical case is the first to show a spontaneous and simultaneous double dissection (of coronary and carotid arteries).

The clinical case highlights the seriousness of cannabis-related cardiovascular complications.

Cannabis is the most widely used illicit drug in the world, its consumption is legalized in some countries.

Cannabis consumption, long considered to have a low cardiovascular risk, is sometimes responsible for serious complications in young subjects with significant sequelae and functional limitation, thus encouraging to limit or even prohibit its marketing.

The second strong point is to show the interest of a medical treatment comprising a double antiplatelet therapy in the treatment of these cases.

The discussion is rich. The authors described the cardiovascular complications associated with cannabis as described in the literature and their management with recent references on this subject.

Figures are clear with visible dissection images in the carotid artery and the proximal left descending artery. I suggest adding an arrow to the pictures. Did you perform a cerebral or coronary imaging control in this patient, if it was the case, please add the pictures?

\section{Is the background of the case's history and progression described in sufficient detail?} Yes 
Are enough details provided of any physical examination and diagnostic tests, treatment given and outcomes?

Yes

Is sufficient discussion included of the importance of the findings and their relevance to future understanding of disease processes, diagnosis or treatment?

Yes

Is the case presented with sufficient detail to be useful for other practitioners?

Yes

Competing Interests: No competing interests were disclosed.

Reviewer Expertise: interventionnal cardiologist

I confirm that I have read this submission and believe that I have an appropriate level of expertise to confirm that it is of an acceptable scientific standard.

The benefits of publishing with F1000Research:

- Your article is published within days, with no editorial bias

- You can publish traditional articles, null/negative results, case reports, data notes and more

- The peer review process is transparent and collaborative

- Your article is indexed in PubMed after passing peer review

- Dedicated customer support at every stage

For pre-submission enquiries, contact research@f1000.com

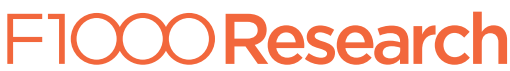

